\title{
The Comparison of Production Workplace Layouts Using Selected Software Tools
}

\author{
Jana Halčinová* , Peter Trebuňa, Iveta Janeková
}

Department of Industrial Engineering and Management, Faculty of Mechanical Engineering, Nemcovej 32, 04200 Košice, Slovak Republik

\section{BIOGRAPHICAL NOTES}

Ing. Jana Halčinová, is an internal PhD. student at the Department of Industrial Engineering and Management of the Faculty of Mechanical Engineering, Technical University in Košice. She graduated at the above - mentioned department in 2011. Her study and research activities cover the field of application of cluster analysis methods in modeling manufacturing and non-manufacturing processes of enterprises.

doc. Ing. Peter Trebuňa, PhD., is associate professor at the Department of Industrial Engineering and Management of the Faculty of Mechanical Engineering, Technical University in Košice. His professional area of activity is oriented of experimental methods and modeling techniques in-house manufacturing and non-manufacturing processes.

Ing. Iveta Janeková, is an internal PhD. student at the Department of Industrial Engineering and Management of the Faculty of Mechanical Engineering, Technical University in Košice. She graduated at the above - mentioned department in 2012. Her study and research activities cover the field of designing production structures, three - dimensional visualization and the utilization of virtual reality in designing production systems.

\section{KEY WORDS}

Plant Simulation; VisTable; layout

\section{ABSTRACT}

The importance of the utilization of software tools when designing production systems is above exception. The current market offers a great deal of options. This article deals with the comparison of two software tools - Plant Simulation and VisTable. It also points to selection criteria you can take into consideration when you are making decision on which product is the most appropriate for your business.

\section{INTRODUCTION}

The features of modern world such as increase of costs, increase of competition, increase of requirements on production shortening and globalization are inciting the manufacturing corporations to attempt to optimise their activities. The vast majority of companies focus the most on the production process and its activities. However one of the most significant areas is the solution of areal disposition (layout) of production systems [1].

When the areal disposition is accurately designed we can accomplish the following positive results [4]:

- minimize costs on manipulation with material,

- effectively utilize all the areas, 
- shorten production cycle and machine attendance time,

\section{- eliminate redundant motions,}

- simplify the communication among personnel and other.

We can accomplish the above - mentioned improvement by using modern software tools. They can also recognize risks which are threatening the production when the areal disposition is designed inaccurately. Their undoubted advantage is that first we can make all alterations without the intervention in real production. As the software purchase represents a considerable cost item it is very important to select the right one [3].

\section{Experimental Section}

The contemporary market offers various software products for the creation of layout from various producers. Examples include VisTable, Factory CAD/Flow, Delmia Process Engineer, Plant Simulation and MPDS4 Factory Layout. In this article we select and compare two of them - Plant Simulation and VisTable. The comparison was done on the basis of knowledge, perceptions and experiences obtained during the creation of layout of production workplace. The following figures depict 2D and 3D layouts designed in each of them. (Fig. 1, Fig. 2, Fig. 3, Fig. 4)

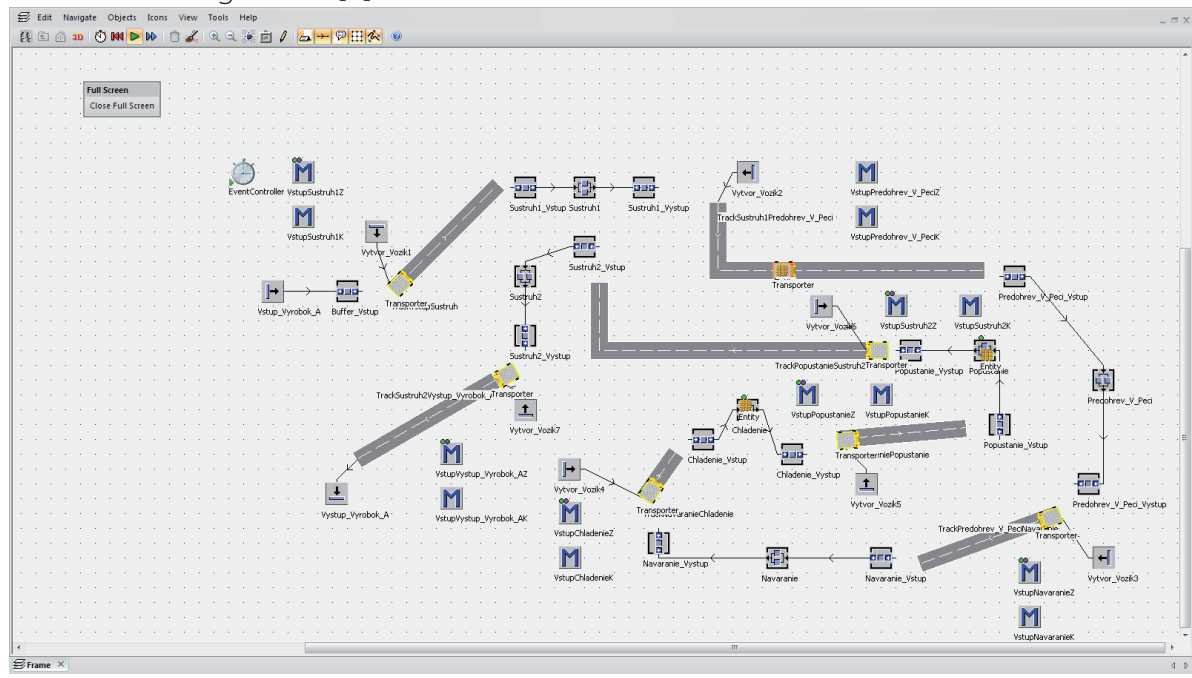

Fig. 1: 2D layout designed in Plant Simulation program.

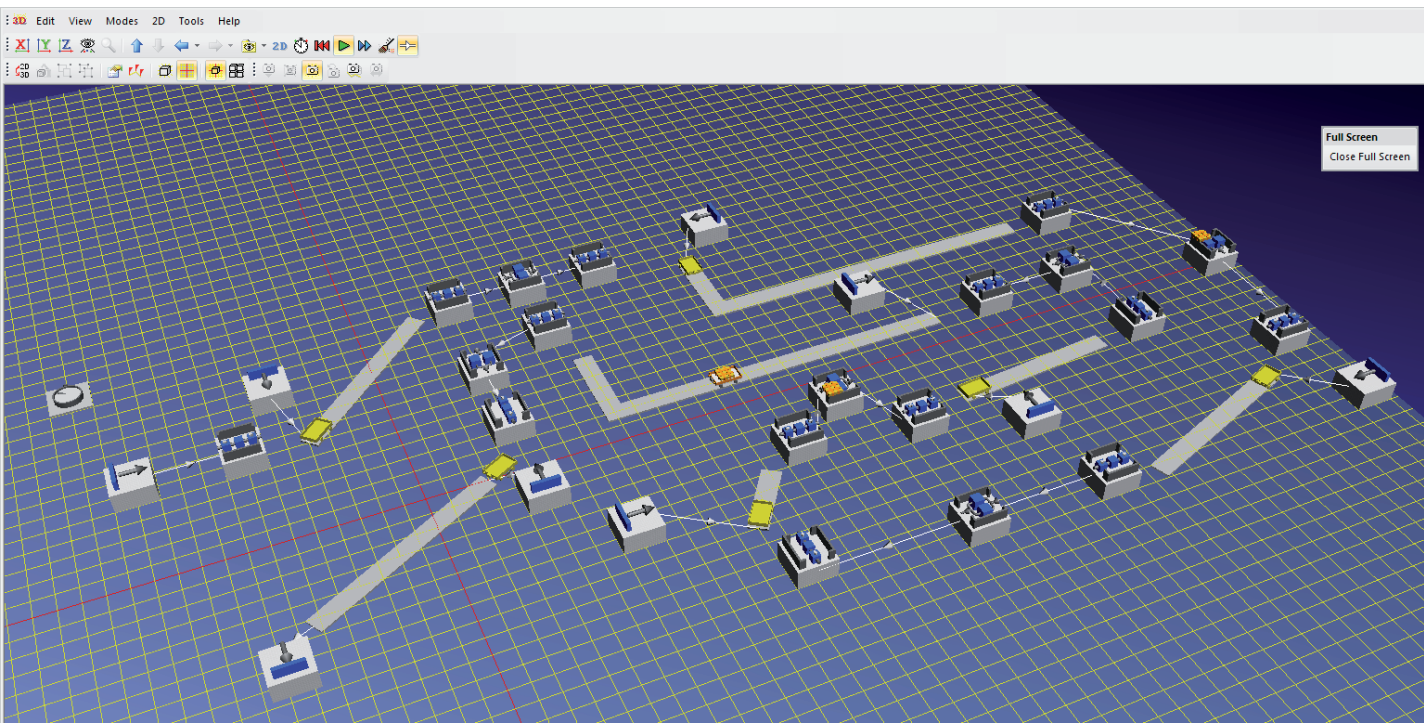

Fig. 2: 3D layout designed in Plant Simulation program. 


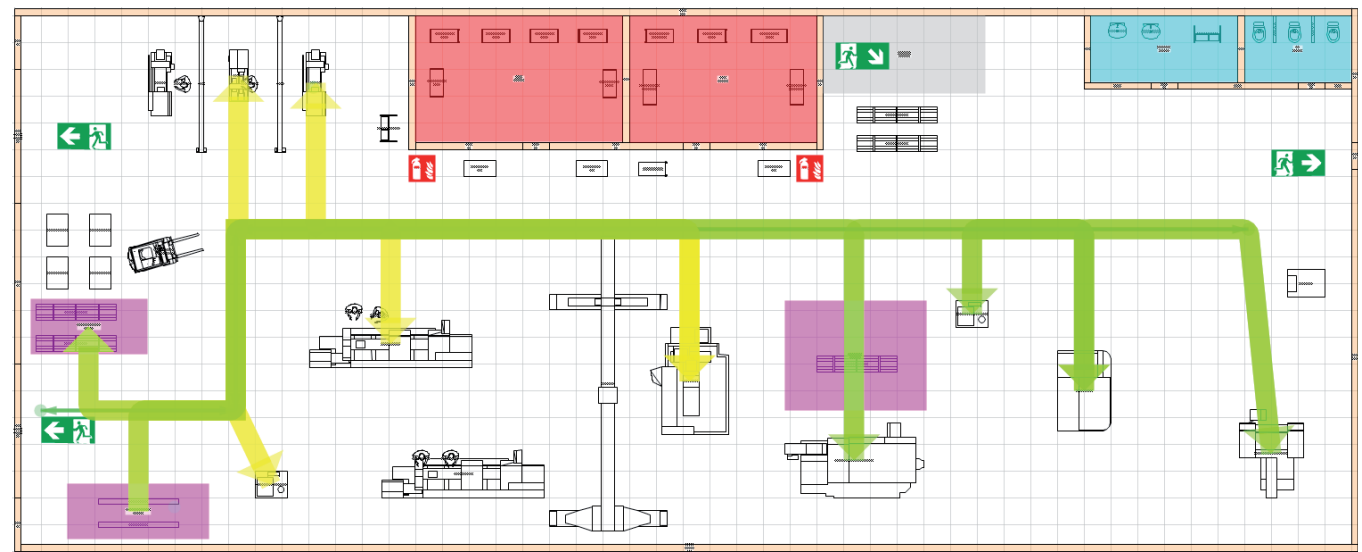

Fig. 3: 2D layout designed in VisTable program.

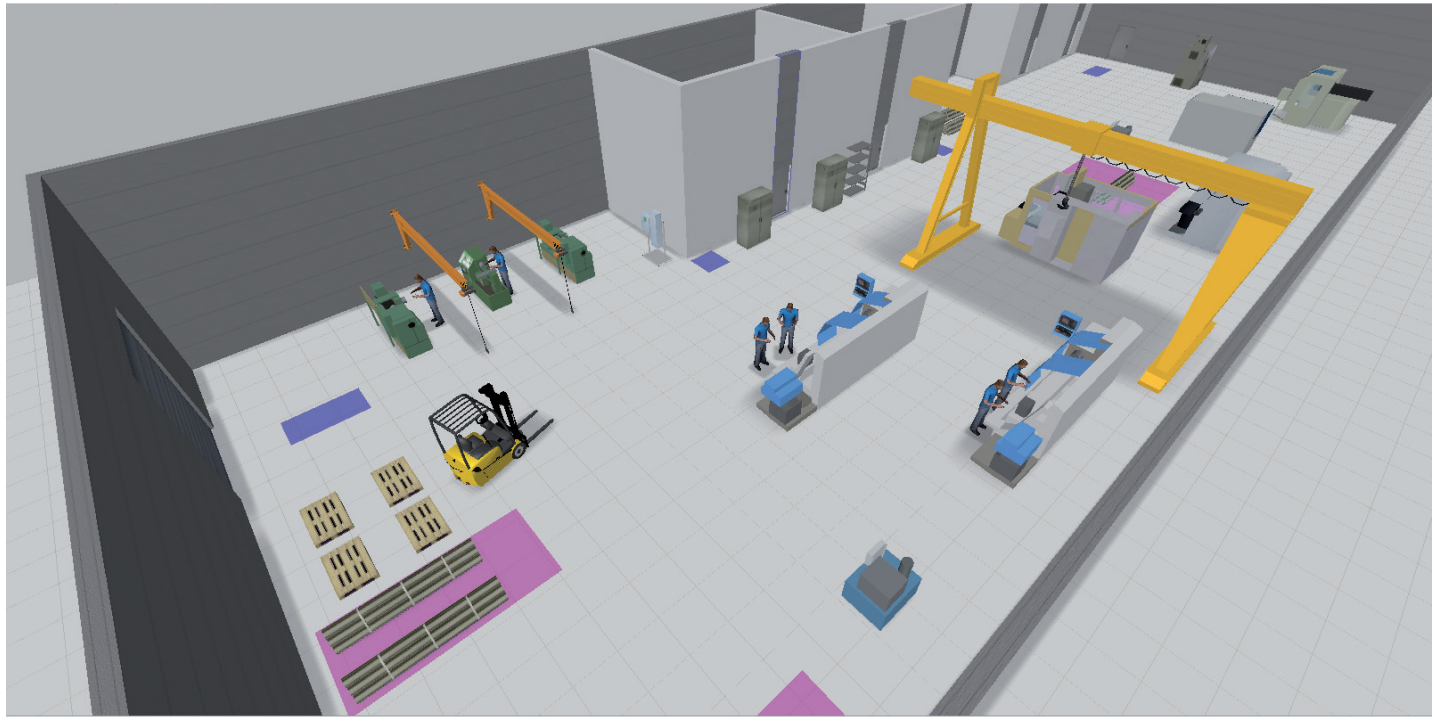

Fig. 4: 3D layout designed in VisTable program.

\section{The Comparison of Software Tools}

In this section we allege obtained perceptions and experiences and compare them from different points of view [2].

\subsection{The graphic interface and work with software tools}

The first thing every user of any software notices is its graphic interface. Graphic interface of Plant Simulation software is similar to Windows application's interface. The environment is created by several panels and toolbars which contain a great deal of icons. In VisTable it is created by one toolbar on which systemic menu is displayed and after object marking dynamic menu is displayed as well. There is a library of resources on the right side. Fig. 5 depicts the difference of graphic interface between selected software [5].
The way of object inserting on the desktop is different in the both software. In Plant Simulation program it is solved by click on the object and click on the desktop called "Frame" and in VisTable program it is solved by marking a pulling the object on the desktop called "Layout".

In case we want to change only the name of the object in Plant Simulation it is not necessary to use the double click, F2 key is enough. When setting the properties of the object in the both programs first it is needed to push the "Apply" button and then confirm it using the "Ok" button.

In Plant Simulation the navigation on the desktop is performed by scroll key. Zoom in and zoom out is performed by scroll key together with Ctrl key or directly by click on the icons situated on the toolbar above the "Frame". 

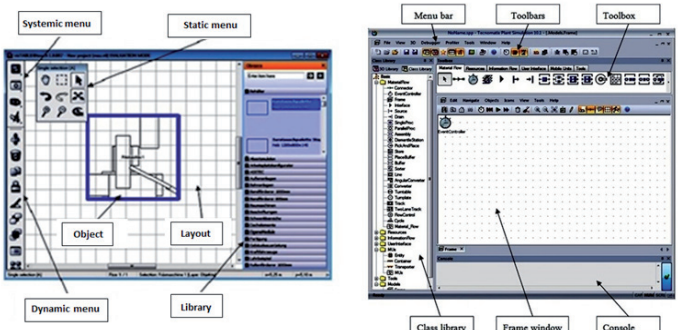

Fig. 5: The comparison of graphic interface, VisTable on the left, Plant Simulation on the right.

The navigation on the desktop in VisTbale is allowed by activating the "Pan" button in the static menu. One of the disadvantages is that for instance if we want to insert the object the navigation on the desktop is automatically deactivated the "Pan" button is inactive and the "Single Selection" button is activated which we use for inserting objects, changing object properties etc. Sometimes this principle is quite chaotic and it would be appropriate to find a better solution. Zoom in and zoom out is accomplished by scroll key or directly through the icons "Increase Zoom" and "Decrease Zoom" in the static menu.

In Plant Simulation software the absence of the button "undo" is very unaccustomed and in many cases it would be handy. VisTable software disposes of this button.

Despite above - mentioned findings we haven't met any other defaults while working with the both software.

\subsection{The library of resources}

In term of display the library of resources is in the both software perceived differently. For instance if we want to insert the object - lathe in Plant Simulation is the machine - lathe displayed only as the icon "ParalleProc" i.e. it is not displayed as a machine. Contrary in VisTable the object - lathe is displayed on the desktop as a machine i.e. machine contour [2]. (Fig. 6).
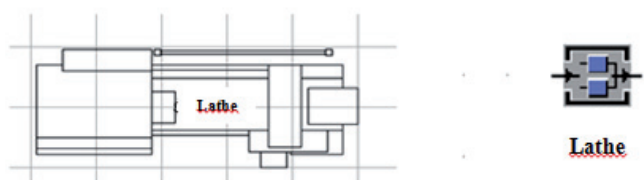

Fig. 6: Object - Lathe in the library of resources, VisTable on the left, Plant Simulation on the right.

In Plant Simulation the library of resources is depicted in a tree structure, in which we can create folders with various numbers of models. Quick access to the objects from the library is through the Toolbox. The library in Plant Simulation id divided into particular folders (Material Flow, Resources, Mobile Units, etc.).

The library of resources in VisTable is an extensive unit. It contains various objects such as structural elements, production machinery, handling technique, storage technique, sanitary facilities and other. In case the library is not sufficient it is possible to import your own objects to the library.

\subsection{Input data for software tools}

The achievement of relevant result or output in the both software is directly proportional to accurate input data.

The basic input data for Plant Simulation software are production time and the period of work piece arrival. Contrary Vistable software doesn't work with any times and its input data are a material flow or the intensity of material flow. The material flow in Vistable is differentiated in colour for various types of products. The intense of material flow is not limited at all for instance by the capacity of particular machines. When inserting the intensity of material flow the program warns us that the inserted intensity value must be from the interval (0.9999999) which we consider to be unlimited.

\subsection{The demandingness for user}

The basic review and familiarization with the both software require certain time. The subjective conclusion is that Vistable is more easily operated because its intuitive handling, less demandingness and less numbers of functions and settings compared to Plant Simulation. In both cases the control language is German whereby they contain English localization [1].

\subsection{Suitability of software tools for the creation of the layout}

From obtained experiences and perceptions while creating the layout in the both software it is necessary to allege that VisTable is more appropriate tool for designing. It results from its close specialization for the creation of layout. Contrary Plant Simulation is more appropriate for modelling and simulation of the production process for purpose of its optimisation. From Siemens Corporation products for instance FactoryCAD would be more appropriate.

When selecting a software tool the most important aspect is to define the purpose for what we 
Table 1: Summary of the comparison.

\begin{tabular}{|l|l|l|}
\hline Comparison & Plant Simulation & VisTable \\
\hline Installation & licence & MS Visio 2010 \\
\hline Systemic requirements & standard & Standard \\
\hline Object insert & mark and click on the screen & mark and pull on the screen \\
\hline Input data & production time & material flow intensity \\
\hline Intuitive handling & no & Yes \\
\hline Constraints & the number of inserted objects & absence of option - save \\
\hline 2D and 3D display & yes (demonstrative) & yes (real) \\
\hline Program stability & yes & Yes \\
\hline Others & absence of button - undo & marking/motion \\
\hline Price & dependant on the number and type of licence & dependant on the number and type of licence \\
\hline Utilization & modelling and simulation of production process & design and optimalization of layout \\
\hline
\end{tabular}

need it so it will meet our expectations. Other issues such as price or demandingness are about determining of priorities. Tab.1 shows a summary of the comparison from various points of view.

\section{Conclusions}

The contribution of software tools for the creation of layout is above exception. Nowadays the proposal and optimisation of the layout are getting on higher level of importance. Regarding selection of software tool it is very important to know the area you are dealing with in detail so you can select the best option for your business. Also you have to define all requirements and expectations you have on the software. The submitted article deals with comparison of two software tools for the creation of layout. The comparison of Plant Simulation and VisTable was created on the basis of layout draft of real production workplace.

\section{Acknowledgments}

This article was created by implementation of the grant project VEGA no. 1/0102/11 Experimental methods and modeling techniques in-house manufacturing and non-manufacturing processes.

\section{References}

[1] BANGSOW,S.: Manufacturing Simulation with Plant Simulation and SimTalk. Berlin. Heidelberg:Springer, 2010. 297 s. ISBN 978-3-642-05073-2.2.

[2] GREGOR,M. et al.: Operačný manažment II., Návody na cvičenia. Žilina: CEIT, a.s., 2012. 87s. ISBN 978-80-970440-3-9.

[3] KOVÁČ, Milan - KOVÁČ, Jozef: Inovačné projektovanie výrobných procesov a systémov. Technická univerzita $\vee$
Košiciach, Univerzitná knižnica, Edícia vedeckej a odbornej literatúry. 2011. 320s. ISBN 978-80-553-0805-0

[4] MALINDŽAK, D. et al..: Modelovanie a simulácia v logistike. Košice. 2009. ISBN 978-80-533-0265-2.

[5] SÄ̈̈KSVUORI, ANTTI - IMMONEN, ANSELMI,: Product lifecycle managment, 2nd ed.. Berlin. 2005. 247s. ISBN 978-3540-78173-8. 


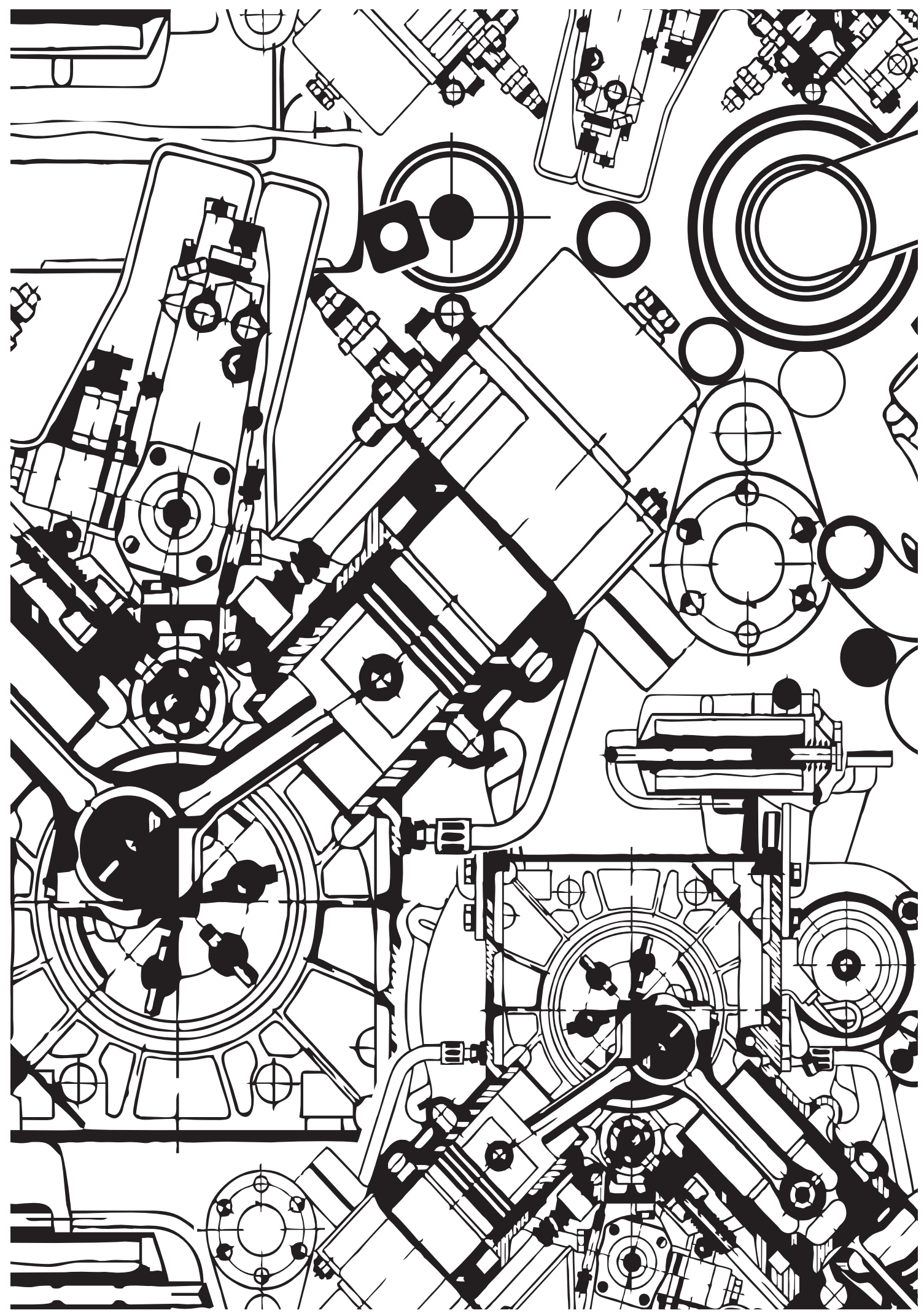

